\title{
A dose of humility
}

\author{
Fiona Godlee editor, The BMJ
}

Paracetamol has come in for a bit of a kicking in recent months (doi:10.1136/bmj.h1186). So we asked James Dear and colleagues to comment (doi:10.1136/bmj.h3705). They confirm that important questions about this most commonly used drug remain unanswered. The evidence of effectiveness is patchy and depends on the condition: it's good for postoperative dental pain; okay for headache, though not as good as other analgesics; of small and probably clinically irrelevant benefit for hip and knee pain; no better than placebo for back pain; and without enough evidence of benefit for the common cold. As for its safety, nearly 60 years of widespread use are reassuring. But there are simmering concerns about subclinical liver and cardiovascular effects and questions about whether or not to intervene in cases of small therapeutic overdose.

So, no clean bill of health for paracetamol, but it's effective for some conditions, and like all drugs it should be used with care. What then of two other commonly prescribed types of drugs: antidepressants and non-steroidal anti-inflammatory drugs? Both types are associated with gastrointestinal bleeding but not, when used alone, with intracranial haemorrhage. However, Ju-Young Shin and colleagues have found that, when these two classes of drugs are used together, as they often are, there is an increased risk of intracranial haemorrhage (doi:10.1136/bmj. $\mathrm{h} 3517)$. They base their conclusions on a retrospective population cohort study of more than four million people in Korea.

In a linked editorial Stewart Mercer and colleagues call the increased risk substantial: the absolute risk in the first 30 days of combined treatment is around $0.05 \%$ when compared with antidepressants alone (doi:10.1136/bmj.h3745). They also say that the risk in people treated for longer periods may be considerably higher. This clearly presents challenges for clinical practice. Pain and depression often go hand in hand, and guidelines are not good at dealing with multimorbidity and polypharmacy. Under these circumstances, they say, knowing patients and their wishes well and "taking an empathic, person centred approach may be as important as having better guidelines and a better evidence base."

Does homeopathy offer a harm free alternative for these common ailments? Yes, says Peter Fisher in a Head to Head article (doi:10.1136/bmj.h3735). Several large observational studies have concluded that doctors who use homeopathy in their practice have better patient outcomes at equivalent cost and use fewer antimicrobial drugs. Doctors should recommend it as part of integrated care, he says. His opponent, Edzard Ernst, is not impressed. He uses 134 of his 909 words on zeros, to press the point that one of the most commercially successful homeopathic remedies cannot contain a single active molecule. Agreeing with the findings of a recent "comprehensive, independent, and rigorous" evaluation, he finds no good evidence that homeopathy works other than through non-specific and placebo effects.

Claims that homeopathic remedies are at worst harmless leave him equally cold. "Even a placebo can cause harm, if it replaces an effective therapy," he says.

I too am unconvinced by homeopathy. But the other stories in this week's journal suggest the need for a good dose of humility about some conventional medicines too. And no harm will be done-indeed there is good evidence of benefit, says Ernst-if we make compassion and empathy an essential part of the therapeutic package.

Cite this as: BMJ 2015;351:h3857

๑ BMJ Publishing Group Ltd 2015 